DOI: https://doi.org/10.11144/Javeriana.upsy16-3.eips

\title{
Emotional Intelligence in Colombian Primary School Children. Location and Gender
}

\section{Inteligencia emocional en niños colombianos de educación primaria. Análisis por contexto y género}

Received: 05 February 2015 | Accepted: 27 February 2017

\author{
Lucía Herrera ${ }^{\mathrm{a}}$ \\ Granada University, España \\ ORCID: http://orcid.org/0000-0002-5860-1357 \\ Rafael E. Buitrago \\ Pedagogical and Technological University of Colombia, \\ Colombia \\ Sergio Cepero \\ Granada University, España
}

a Correspondance author. E-mail: luciaht@ugr.es

How to cite: Herrera, L., Buitrago, R. E., Cepero, S. (2017). Emotional Intelligence in Colombian Primary School Children. Location and Gender Analysis. Universitas Psychologica, 16(3), 1-10. https://doi.org/ 10.11144/Javeriana.upsy16-3.eips

\begin{abstract}
This paper analyses Emotional Intelligence (EI) in Colombian Primary School Children depending on their location (rural or urban) and gender. The final sample consisted of 1451 students in fourth and fifth grade of three provinces in the Boyacá department. Emotional Quotient Inventory: Youth Version ([EQ-i: YV]; Bar-On \& Parker, 2000) was used for data collection. Both the reliability and validity of EQ-i: YV have been determined for this sample. The main results revealed differences in EI according to location. Overall, EI was higher in urban than in rural settings. Also, scores on the interpersonal and adaptability dimensions differed by gender. Additionally, the need for future research and development of Social and Emotional Learning programs in schools is discussed.

Keywords

emotional intelligence; Colombian children; primary school; location; gender
\end{abstract}

\section{RESUMEN}

Este artículo analiza la Inteligencia Emocional (IE) de niños colombianos de educación primaria en función de su contexto (rural o urbano) y género. La muestra final fue de 1451 estudiantes de cuarto y quinto curso de tres provincias del departamento de Boyacá. Se empleó el Inventario de Cociente Emocional: versión para jóvenes ([EQ-i: YV]; Bar-On \& Parker, 2000) para la recogida de información. Tanto la fiabilidad como la validez del EQ-i: YV fueron determinados para esta muestra. Los resultados principales revelaron diferencias en la IE de acuerdo con el contexto. En general, la IE fue más alta en el contexto urbano que en el rural. Además, las puntuaciones en las dimensiones interpersonal y adaptabilidad diferían según el género. Adicionalmente, la necesidad de futuras investigaciones y el desarrollo de programas de aprendizaje socio-emocional en las escuelas son discutidas.

Palabras clave

inteligencia emocional; niños colombianos; escuela primaria; contexto; género 


\section{Analysis}

Emotional Intelligence (EI) is a construct that has aroused interest in psychological research in recent decades (Bar-On, 2010; Stough, Saklofske, \& Parker, 2009). The first authors who proposed a formal definition model of EI were Salovey and Mayer (1990), defining it as "the subset of social intelligence that involves the ability to monitor one's own and others' feelings and emotions, to discriminate among them, and to use this information to guide one's thinking and actions" (p. 189). However, there has been controversy about the origin and theoretical nature of EI models (Cherniss, 2010; MacCann, 2010). On the one hand we have models based on the processing of emotional information, that is, focused on basic emotional abilities (Brackett, Rivers, \& Salovey, 2011; Mayer \& Salovey, 1997); on the other hand, there are mixed models of EI, which involve both intellectual and personality factors. Within this second conceptual approach the trait EI model by Petrides and Furnham (2001), the socio-emotional competence model by Bar-On (1997, 2006), and the emotional competencies model focused on workplace by Goleman (1995) are identified. Thus, BarOn (2006) proposes the term Socio-Emotional Intelligence (SEI), which "is a cross-section of social and emotional interrelated competencies, skills, and facilitators that determine how we understand and effectively express ourselves, understand others and relate with them, and cope with daily demands" (p. 14).

Currently, research on EI focuses on the need to establish the use and role of EI in several people's vital features, and to assess the relationship between EI and other important criterion variables in the development and wellbeing of individuals (Petrides et al., 2010; Zeidner, Matthews, \& Roberts, 2012). Thus, a close relationship among EI, coping styles, and academic performance can be identified (MacCann, Fogarty, Zeidner, \& Roberts, 2011). Students with high EI are evaluated by their peers and teachers better than those with low EI, showing more prosocial and less aggressive behavior (Petrides, Sangareau, Furnham, \& Frederickson, 2006), greater empathy as a factor that enhances school life (Duffel, Beland, \& Frey, 2006), better transition from primary school to high school, better academic performance and self-assessment, in addition to a higher attendance and behavioral adjustment (Qualter, Whiteley, Hutchinson, \& Pope, 2007).

Therefore, the relevance of EI might be identified by the indicators on personal and academic success (Pekrun, Elliot, \& Maier, 2009; Saklofske, Austin, Mastoras, Beaton, \& Osborne, 2012). So, EI must be developed in school from both prevention and intervention programs (Durlak, Weissberg, Dymnicki, Taylor, \& Schellinger, 2011; Saadi, Honarmand, Najarian, Ahadi, \& Askari, 2012). Eventually, the description becomes consistent with the demands from Positive Psychology regarding the establishment of safe environments and positive emotions in the classroom, in order to facilitate the development and wellbeing of students (Park \& Peterson, 2008; Seligman, Ernst, Guillham, Reivich, \& Linkins, 2009).

Other studies find gender differences in EI. Consequently, in the models which consider the EI as a set of cognitive skills (Mayer, Salovey, $\&$ Caruso, 2000), women performed better in EI skills than men (Joseph \& Newman, 2010). Similarly, studies which used the EQ-i as a measuring instrument of EI, found that men score higher in the adaptability and general mood domains, while women score higher in the interpersonal and intrapersonal domains, and in Total EQ (Bar-On \& Parker, 2000; Ferrándiz, Hernández, Bermejo, Ferrando, \& Sáinz, 2012; Santesso, Reker, Schmidt, \& Segalowitz, 2006). To explain these differences, the need to go beyond the scope of sexual differences in EI must be emphasized in and non-stereotyped referents of gender identity promoted (Conway, 2000). Gender differences in EI are detected since childhood; these may be caused by an emotional instruction different between boys and girls (Brackett \& Salovey, 2006).

Despite what has been described so far, and the fact that all children are entitled to have quality education regardless of their geographic 
location and socio-economic conditions -which stimulates their global development in different areas (United Nations Educational, Scientific and Cultural Organization [UNESCO], 2005)the reality is that this does not always happen (UNESCO, 2011). Overall through developing countries, the gap between urban and rural settings remains static or gets bigger (Rimisp - Centro Latinoamericano para el Desarrollo Rural, 2012; Whitfield, 2012), which is determined by geographical, cultural, organizational, and economic factors (Esteves, 2012; Richards et al., 2011). This shows that an elevated percentage of the rural population is living in poverty which, coupled with the high levels of heterogeneity in Latin America (Bértola, Prados, \& Williamson, 2010), facilitates inequality between public and private education; this is also seen amongst urban, marginal urban, and rural areas; and between indigenous and non-indigenous populations (McEwan, 2008; Stelmach, 2011; Torche, 2010).

The situation described above has motivated the current research on the topic of rural and urban settings of Colombia. There are few studies on EI in the country. One of them is the study of Cerón, Pérez-Olmos, and Ibáñez (2011), which assesses the EI of adolescents between 12 and 17 years of age. The results displayed the relationship concerning perceived EI and gender, with women scoring higher.

According to what we have described so far, the main objective of this research was to analyze the EI, using the Bar-On Model of Emotional and Social Intelligence (1997, 2006), of children attending fourth and fifth grade of primary school, from the department of Boyacá in Colombia, taking into account their location (rural vs. urban) and gender.

\section{Method}

\section{Participants}

The study was carried out with an initial sample of 1876 students. After the elimination of invalid cases, applying the inconsistency index of the EQ- i: YV, the final sample consisted of 1451 students: 727 girls $(50.1 \%)$, and 724 boys (49.9\%), with a mean age of 10.38 years, $S D=1.12$. Children studied fourth grade, $n=638(44 \%)$, and fifth grade of primary school, $n=813(56 \%)$; in rural educational institutions, $n=690$ (47.6\%), and urban institutions, $n=761$ (52.4\%). Participants lived in one of the following three provinces of Boyacá in Colombia: Centro, $n=478$ (32.9\%), Tundama, $n=483$ (33.3\%), and Sugamuxi, $n=$ 490 (33.8\%).

The sample distribution, according to their location and gender, consisted of 344 girls in the rural areas (49.85\%), and 346 boys $(50.15 \%)$. The urban areas included 383 girls (50.32\%), and 378 boys $(49.68 \%)$. The proportion of students from rural and urban areas in each of the three provinces was almost the same. Thus, in the Centro province, $49.6 \%$ lived in a rural area $(n=237)$, and $50.4 \%$ in an urban area $(n=$ $241)$; in the Tundama province, $45.8 \%$ lived in a rural location $(n=221)$, and $54.2 \%$ in an urban location $(n=262)$; and in the Sugamuxi province, $47.3 \%$ lived in a rural location $(n=$ $232)$, and $52.7 \%$ in an urban location $(n=258)$.

\section{Instrument}

Emotional Quotient Inventory: Youth Version (EQi: YV, Bar-On \& Parker, 2000) was used for the development of this study. It is a selfreport instrument designed to measure emotional intelligence in young people. It consists of 60 items and is composed of five scales or domains: intrapersonal, with 6 items; interpersonal, 12 items; stress management, 12 items; adaptability, 10 items; and general mood, 14 items. The first four scales generate the Total EQ, being the general mood a facilitator of it. Finally, it also has two scales that control the validity of the test. The positive impression scale, consisting of six items, allows spotting cases with an exaggerated positive perception (cases with standard scores above 130 are invalidated); and the inconsistency index (cases that reach a value equal to or greater than 10 are invalidated), by reflecting a high number of random responses. 
The BarOn EQ-i: YV is suitable for children and adolescents within the age range from 7 to 18 years. Subjects had to respond to a Likert scale of four points $(1=$ Very Seldom or Not True of Me, 4 = Very Often or True of Me). For correction, scales are presented by gender and age groups (7-9, 10-12, 13-15, and 16-18 years). Direct scores allow to obtain three measures: Standard Scores; Level (Markedly Low, Very Low, Low, Average, High, Very High, and Markedly High), and Percentiles. In addition to estimate the level of EI, it generates an emotional and social profile. In this sense, Mayer et al. (2000) consider this model as a mixed model, which integrates social, emotional, cognitive, and personality dimensions.

Psychometric requirements regarding test validity and reliability are guaranteed (BarOn \& Parker, 2000), in addition to being confirmed in different populations, such as Hungarian (Kun et al., 2012) and Spanish (Ferrándiz et al., 2012). Construct validity has been confirmed for this study. Thus, to verify the adequacy of the test, a Factorial Analysis was conducted, the Kaiser-Meyer-Olkin index (KMO), with a value of 0.724 , and the Bartlett's sphericity test, $\chi^{2}=35.932, p=0$, were obtained. Later, an Exploratory Factor Analysis using Principal Components Extraction with Varimax Rotation was developed, explaining $45.629 \%$ of the total variance and obtaining the following distribution of factors: general mood $(11.960 \%)$, stress management $(9.624 \%)$, adaptability $(9.018 \%)$, interpersonal $(8.802 \%)$, and intrapersonal (6.225\%).

Similarly, the overall reliability of the test was calculated with a value of .802 for Cronbach's alpha, and for each dimension: intrapersonal $(\alpha=0.634)$, interpersonal $(\alpha=0.751)$, stress management $(\alpha=0.786)$, adaptability $(\alpha=$ $0.727)$, and general mood $(\alpha=0.813)$.

\section{Procedure}

For this study, it was necessary to obtain the approval and authorization of the Secretaries of the Education Department of Boyacá and from the three provinces (in the municipalities of Tunja, Duitama, and Sogamoso). Once obtained, a classroom was provided in each of the schools, which was usually the regular classroom, so that students could complete the instrument, previously having been given the required instructions to answer the test.

Once the data was collected, invalid cases were removed, those who obtained a value equal to or greater than 10 in the inconsistency index of the EQ-i: YV, $n=425$. Furthermore, there were no cases with a standard score on the dimension positive impression equal to or greater than 130, Minimum =63, Maximum $=118, \mathrm{M}$ $=90.69, \mathrm{SD}=11.46$. The Statistical Package SPSS for Windows (version 19.0) was used for data analysis. Descriptive statistics (mean and standard deviation) were calculated for data representing, and analysis of variance was developed for quantitative analysis of the studied variables.

\section{Results}

First, the mean score obtained in each of the five EQ-i: YV (expressed in standard scores, level, and percentiles), together with the overall EQ, are shown in Table 1.

\section{TABLE 1}

Descriptive Statistics on the EQ-i: YV

\begin{tabular}{lcccccc}
\hline & \multicolumn{3}{c}{ Standard Score } & \multicolumn{2}{c}{ Level } & \multicolumn{2}{c}{ Percentile } \\
\cline { 2 - 7 } EQ-i: YV & $M$ & $S D$ & $M$ & $S D$ & $M$ & $S D$ \\
\hline Intrapersonal & 98.72 & 11.23 & 3.92 & 0.82 & 54.68 & 15.71 \\
Interpersonal & 91.19 & 10.81 & 3.39 & 0.91 & 35.24 & 9.71 \\
Stress Management & 96.33 & 11.18 & 3.75 & 0.79 & 45.73 & 12.76 \\
Adaptability & 99.22 & 12.20 & 3.99 & 0.87 & 52.69 & 14.76 \\
General Mood & 103.74 & 11.63 & 4.22 & 0.73 & 60.97 & 15.71 \\
Total EQ & 96.15 & 10.83 & 3.77 & 0.74 & 44.62 & 11.66 \\
\hline
\end{tabular}

Source: own work.

Following this, we proceeded to determine whether the EI of students was different depending on Location and Gender. In this sense, Table 2 shows the descriptive statistics for the five 
dimensions of EI (in percentiles) and the Total $\mathrm{EQ}$, depending on such variables.

\section{TABLE 2}

Mean (and Standard Deviation) on the EQ-i: YV by Location and Gender

\begin{tabular}{|c|c|c|c|c|}
\hline \multirow[b]{2}{*}{ EQ-i YV } & \multirow[b]{2}{*}{ Gender } & \multicolumn{3}{|c|}{ Location } \\
\hline & & Rural & Urban & Total \\
\hline \multirow{6}{*}{ Intrapersonal } & Ro & 56.95 & 54.85 & 55.85 \\
\hline & Boys & (15.83) & (16.32) & (15.62) \\
\hline & & 51.98 & 54.89 & 53.51 \\
\hline & Girls & (16.94) & (16.41) & (16.74) \\
\hline & Total & 54.47 & 54.87 & 54.68 \\
\hline & lotal & $(15.42)$ & $(16.85)$ & (15.61) \\
\hline \multirow{6}{*}{ Interpersonal } & Boys & 32.81 & 34.90 & 33.32 \\
\hline & Doys & (9.68) & (9.30) & $(9.49)$ \\
\hline & Girls & 34.28 & 38.60 & 36.56 \\
\hline & & (9.13) & $(9.50)$ & (9.39) \\
\hline & & 33.54 & 36.78 & 35.24 \\
\hline & Total & $(9.90)$ & $(9.96)$ & $(9.71)$ \\
\hline \multirow{5}{*}{$\begin{array}{l}\text { Stress } \\
\text { Management }\end{array}$} & Boys & 43.21 & 46.30 & 44.82 \\
\hline & & (11.79) & (12.92) & (12.52) \\
\hline & Girls & $\begin{array}{c}44.56 \\
(12.87)\end{array}$ & $\begin{array}{c}48.49 \\
(12.87)\end{array}$ & $46.63(12)$ \\
\hline & & 43.87 & 47.40 & 45.73 \\
\hline & Total & (12.21) & (12.90) & (12.76) \\
\hline \multirow{6}{*}{ Adaptability } & & 54.62 & 53.78 & 54.18 \\
\hline & Boys & $(14.71)$ & (15.06) & (14.88) \\
\hline & Girls & 48.85 & 53.35 & 51.02 \\
\hline & Gills & (14.53) & (15.34) & (14.98) \\
\hline & Total & 51.74 & 53.56 & 52.69 \\
\hline & lotal & $(14.27)$ & (15.69) & (14.76) \\
\hline \multirow{6}{*}{$\begin{array}{l}\text { General } \\
\text { Mood }\end{array}$} & Boys & 57.85 & 61.61 & 59.81 \\
\hline & & (16.74) & (14.58) & (15.71) \\
\hline & Girls & 60.77 & 63.35 & 62.13 \\
\hline & & (16.86) & (13.18) & (14.04) \\
\hline & Total & 59.30 & 62.48 & 60.97 \\
\hline & 1otal & $(16.82)$ & (14.88) & (15.71) \\
\hline \multirow{5}{*}{ Total EQ } & Boys & 43.74 & 45.38 & 44.60 \\
\hline & & (12.53) & $(10.16)$ & $(11.85)$ \\
\hline & Girls & $\begin{array}{c}41.58 \\
(12.48)\end{array}$ & $\begin{array}{c}47.38 \\
(1061)\end{array}$ & $\begin{array}{c}44.64 \\
\end{array}$ \\
\hline & & 42.66 & 46.39 & 44.62 \\
\hline & lotal & (12.51) & (10.39) & (11.66) \\
\hline
\end{tabular}

A variance analysis was conducted with repeated measures $6 \times 2 \times 2$, in which EI was introduced as within-subjects factor, with the five dimensions of EQ-i: YV and the Total EQ; Location (rural, urban) and Gender (boy, girl) were the between-subjects factors. Because the assumption of sphericity was not meet, Mauchly's $W=0.211, \chi^{2}=2248.263, d f=14, p=0$, the results were interpreted taking into account the Wilks' Lambda test. The main results are presented in Table 3.
TABLE 3

Main Results for ANOVA on the EQ-i: YV

\begin{tabular}{|c|c|c|c|c|}
\hline & & $F$ & $p$ & $\eta_{p}{ }^{2}$ \\
\hline \multicolumn{2}{|l|}{$\mathrm{EI}$} & 337.851 & $0 * * *$ & 0.539 \\
\hline \multicolumn{2}{|l|}{ Location } & 7.561 & $0.006 * *$ & 0.013 \\
\hline \multicolumn{2}{|l|}{ Gender } & 0.031 & 0.859 & 0 \\
\hline \multicolumn{2}{|l|}{$\begin{array}{l}\text { Location } \\
\text { Gender }\end{array}$} & 2.002 & 0.157 & 0.001 \\
\hline \multicolumn{2}{|l|}{ Location } & 3.603 & $0.003 * *$ & 0.012 \\
\hline \multicolumn{2}{|c|}{ EI x Gender } & 5.670 & $0 * * *$ & 0.019 \\
\hline EI & $\mathrm{x}$ & & & \\
\hline Location & $\mathrm{x}$ & 1.162 & 0.326 & 0.004 \\
\hline Gender & & & & \\
\hline
\end{tabular}

The main effect of EI was significant, Wilks' Lambda $=.461, F(5,1445)=337.851, p=$ $0, \eta p{ }^{2}=0.539$. The pairwise comparisons, by means of Bonferroni's test, showed significant differences between the intrapersonal dimension and interpersonal, $t=19.510, p=0$, stress management, $t=9.031, p=0$, general mood, $t$ $=6.225, p=0$, and Total EQ, $t=10.146, p=0$; between the interpersonal dimension and stress management, $t=10.479, p=0$, adaptability, $t$ $=17.491, p=0$, general mood, $t=25.736, p$ $=0$, and Total EQ, $t=9.365, p=0$; in stress management versus adaptability, $t=7.011, p=$ 0 , and general mood $, \mathrm{t}=15.256, p=0$; between the dimensions adaptability and general mood, $t$ $=8.245, p=0$, in addition to the Total EQ, $t$ $=8.126, p=0$; and between general mood and Total EQ, $t=16.637, p=0$.

Also, the main effect of Location was significant, $F(1,1449)=7.561, p=0.006$, $\eta p^{2}=0.013$, so that rural students scored significantly lower than those in the urban context, $M_{\text {rural }}=47.600, S D=13.657 ; M_{\text {urban }}$ $=50.246, S D=13.626$, as reflected in the posthoc comparisons, $t=2.646, p=0.006$.

Interaction between EI x Location reached the level of statistical significance, Wilks' Lambda 
$=.988, F(7,2894)=3.603, p=0.003, \eta_{p}$

$2=0.012$. Although, in general, the EI was higher in urban than in rural areas, no differences were found in the intrapersonal, $t=0.397, p=$ 0.782 , and adaptability dimensions, $t=1.825, p$ $=0.231$. Finally, the interaction EI $x$ Gender was significant, Wilks' Lambda $=0.981, F(7,2894)$ $=5.670, p=0, \eta p^{2}=0.019$. In this sense, girls scored higher than boys in the interpersonal dimension, $t=3.041, p=0.50$, while boys scored higher than girls in the adaptability dimension, $t$ $=3.162, p=0.048$.

\section{Discussion}

In this paper the psychometric properties of the EQ-i: YV for the sample of Colombian student participants has been determined, specifically construct validity and reliability, or internal consistency of the test, confirming results from previous research with populations from other countries (Bar-On \& Parker, 2000; Ferrandiz et al., 2012; Kun et al., 2012). Moreover, the overall scores on the EQ-i: YV of students, based on standard scores, level, and percentiles, are in the mean, except in the interpersonal dimension, which has a lower level of development. Interpersonal relationships in school are directly related to indicators of academic success and personal and social adjustment, so that children have more and quality friends from an early age, in order to create social networks that contribute to their development and reduce the emergence of certain behaviors, such as exclusion and aggression (Pekrun et al., 2009; Petrides et al., 2006). Schools should directly influence the development of this dimension of EI, by promoting those skills related to empathy, social responsibility, and interpersonal relationships in the classroom (Bar-On, 2006; Duffel et al., 2006).

Regarding the results of the analysis of variance, a differentiated pattern in the EI of students has been found. Thus, the dimension with a higher level of development is the general mood, which reflects the skills to maintain a positive attitude in life (optimism and happiness) and, although not part of the emotional quotient or Total EQ obtained in EQ-i: YV, it is a dimension that facilitates it (Bar-On \& Parker, 2000). In second place there are the dimensions intrapersonal, the skills to understand one's own emotions and communicating them to others, and adaptability, that is, flexibility and efficiency in resolving conflicts. Thirdly, it identifies stress management, which involves the skill to manage and control one's emotions, and Total EQ; being in last place, as mentioned above, the interpersonal dimension, that is, the ability to understand and value others' emotions.

Furthermore, it reveals a clear differentiation between rural and urban context in EI, which is consistent with studies indicating heterogeneity between the two contexts in the Latin American field (Rimisp, 2012; Torche, 2010). These differences are marked by the difficult access to rural schools, the contrast in infrastructure and quality of educational materials between the two sectors, in addition to the curriculum with "urban bias", which makes it unsuitable given its lack of contextualization. Educational advancement of the rural sector requires specific educational activities, improving school infrastructure, food, health, basic educational equipment, the implementation of educational policies aimed at improving the quality of education, initial and continuing teachings, and improving wage conditions and teacher incentives (Stelmach, 2011). Similarly, there is an education in rural habitat, but not an education for rural people that is clearly contextualized and created with the participation of rural and indigenous communities (UNESCO, 2011).

Schools have to facilitate global development of children and youth, focusing on their social and emotional development (Saklofske et al., 2012; UNESCO, 2005), through a classroom atmosphere that enhances safe and positive emotions towards the happiness of students (Extremera, Ruiz-Aranda, Pineda, \& Salguero, 2011; Seligman et al., 2009). Because of this, Social and Emotional Learning (SEL) has to be integrated as part of the curricula in the context 
of rural education, that is to say, the stimulation of EI (Durlak et al., 2011; Saadi et al., 2012).

Moreover, differences by gender in two EI dimensions are found. The superiority of girls in the interpersonal dimension confirms the results of previous research (Cerón et al., 2011; Santesso et al., 2006). So, girls show greater competences and abilities than boys in empathy, social responsibility, and extrovert relations. However, boys score higher on the adaptability dimension (Ferrandiz et al., 2012), that is, overlapping with reality, being flexible, and problem-solving. These differences between men and women could be due to cultural factors and family rearing practices differentiated by gender, in the same direction as other studies suggest (Conway, 2000; Joseph \& Newman, 2010).

Finally, although this study cannot be generalized to the Latin American context, which is highly diverse, it is necessary to research deeply EI in rural and urban locations by analyzing social, cultural, educational, and family factors. Gender and culture are two factors that from research in Psychology have been widely debated and studied in recent decades, resulting in emerging new conceptions that affect theory and practice (Magnusson \& Marecek, 2012; Valsiner, 2012). Also, different types of measuring instruments (self-report measures and performance measures) should be combined in future studies (Brackett \& Salovey, 2006; Mayer et al., 2000; Petrides et al., 2010).

\section{Acknowledgements}

This research was supported by the Research Group "Development, Education, Diversity, and Culture: An Interdisciplinary Analysis" (HUM-742), Andalusian Plan for Research, Development and Innovation, Spain. Also, it was co-financed by the Vice-Rectorate for Research and Knowledge Transference of the University of Granada, Spain (Program 20. Target-Based Funding. 2015-17 Contract Program).

\section{References}

Bar-On, R. (1997). The BarOn Emotional Quotient Inventory (EQ-i): Technical manual. Toronto, Canada: Multi-Health Systems Inc.

Bar-On, R. (2006). The Bar-On Model of Emotional-Social Intelligence (ESI). Psicothema, 18(Special Issue), 13-25.

Bar-On, R. (2010). Emotional intelligence: An integral part of positive psychology. South African Journal of Psychology, 40(1), 54-62. http:// dx.doi.org/10.1177/008124631004000106

Bar-On, R., \& Parker, J. (2000). BarOn Emotional Quotient Inventory: Youth Version (BarOn EQi:YV), Technical Manual. Toronto, Canada: Multi-Health Systems Inc.

Bértola, L., Prados, L., \& Williamson, J. G. (2010). Latin American inequality in the long run. Journal of Iberian and Latin American Economic History, 28(2), 219-226. http://dx.doi.org/10.1017/ S0212610910000054

Brackett, M., Rivers, S. E., \& Salovey, P. (2011). Emotional intelligence: Implications for personal, social, academic, and workplace success. Social and Personality Psychology Compass, 5(1), 88-103. http://dx.doi.org/10.1111/ j.1751-9004.2010.00334.x

Brackett, M., \& Salovey, P. (2006). Measuring emotional intelligence with the MayerSalovery-Caruso Emotional Intelligence Test (MSCEIT). Psicothema, 18(Special Issue), 34-41.

Cerón, D. M., Pérez-Olmos, I., \& Ibáñez, M. (2011). Inteligencia emocional en adolescentes de dos colegios de Bogotá. Revista Colombiana de Psiquiatría, 40, 49-64. http://dx.doi.org/10.1016/ S0034-7450(14)60104-9

Cherniss, C. (2010). Emotional intelligence: Toward clarification of a concept. Industrial and Organizational Psychology, 3(2), 110-126. http://dx.doi.org/10.1111/ j.1754-9434.2010.01231.x 
Conway, M. (2000). On sex roles and representation of emotional experience: Masculinity, femininity and emotional awareness. Sex Roles, 43(9-10), 687-698. http:// dx.doi.org/10.1023/A:1007156608823

Duffel, J. C., Beland, K., \& Frey, K. (2006). The second step program: Social-emotional skills for violence prevention. In J. J. Elias \& H. Arnold (Eds.), The educator's guide to emotional intelligence and academic achievement: Emotional learning in the classroom (pp. 161-171). Thousand Oaks, CA: Corwin Press.

Durlak, J. A., Weissberg, R. P., Dymnicki, A. B., Taylor, R. D., \& Schellinger, K. B. (2011). The impact of enhancing students' social and emotional learning: A meta-analysis of schoolbased interventions. Child Development, 82 (1), 405-432. http://dx.doi.org/10.1111/ j.1467-8624.2010.01564.x

Esteves, R. (2012). The quest for equity in Latin America: A comparative analysis of the health care reforms in Brazil and Colombia. International Journal for Equity in Health, 11(6). http:// dx.doi.org/10.1186/1475-9276-11-6

Extremera, N., Ruiz-Aranda, D., Pineda, C., \& Salguero, J. M. (2011). Emotional intelligence and its relation with hedonic and eudaimonic well-being: A prospective study. Personality and Individual Differences, 51, 11-16. http:// dx.doi.org/10.1016/j.paid.2011.02.029

Ferrándiz, C., Hernández, D., Bermejo, R., Ferrando, M., \& Sáinz, M. (2012). Social and emotional intelligence in childhood and adolescence: Spanish validation of a measurement instrument. Journal of Psychodidactics, 17(2), 309-338. http:// dx.doi.org/10.1387/Rev.Psicodidact.2814

Goleman, D. (1995). Emotional intelligence. New York: Bantam Books.

Joseph, D. L., \& Newman, D. A. (2010). Emotional intelligence: An integrative meta-analysis and cascading model. Journal of Applied Psychology, 95(1), 54-78. http:// dx.doi.org/10.1037/a0017286

Kun, B., Urbán, R., Paksi, B., Csóbor, L. V., Oláh, A., \& Demetrovics, Z. (2012). Psychometric characteristics of the Emotional Quotient Inventory, Youth Version, Short Form, in Hungarian high school students. Psychological Assessment, 24(2), 518-523. http://dx.doi.org/10.1037/ a0026013

MacCann, C. (2010). Further examination of emotional intelligence as a standard intelligence: A latent variable analysis of fluid intelligence, crystallized intelligence, and emotional intelligence. Personality and Individual Differences, 49(5), 490-496. http://dx.doi.org/10.1016/ j.paid.2010.05.010

MacCann, C., Fogarty, G. J., Zeidner, M., \& Roberts, R. D. (2011). Coping mediates the relationship between emotional intelligence (EI) and academic achievement. Contemporary Educational Psychology, 36(1), 60-70. http:// dx.doi.org/10.1016/j.bbr.2011.03.031

Magnusson, E., \& Marecek, J. (2012). Gender and culture in psychology: Theories and practices. Cambridge, UK: Cambridge University Press.

Mayer, J. D., \& Salovey, P. (1997). What is emotional intelligence? In P. Salovey \& D. Sluyter (Eds.), Emotional development and emotional intelligence: Implications for educators (pp. 3-31). New York: Basic Books.

Mayer, J. D., Salovey, P., \& Caruso, D. R. (2000). Mayer-Salovey-Caruso Emotional Intelligence Test (MSCEIT) item blocket. Research version. Toronto, Canada: MHS Publishers.

McEwan, P. J. (2008). Evaluating multigrade school reform in Latin America. Comparative Education, 44(4), 465-483. http:// dx.doi.org/10.1080/03050060802481504

Park, N., \& Peterson, C. (2008). Positive psychology and character strengths: Application to strengths-based school 
counseling. Professional School Counseling, 12(2), 85-92. http://dx.doi.org/10.5330/ PSC.n.2010-12.85

Pekrun, R., Elliot, A. J., \& Maier, M. A. (2009). Achievement goals and achievement emotions: Testing a model of their joint relations with academic performance. Journal of Educational Psychology, 101(1), 115-135. http:// dx.doi.org/10.1037/a0013383

Petrides, K. V., \& Furnham, A. (2001). Trait emotional intelligence: Psychometric investigation with reference to established trait taxonomies. European Journal of Personality, 15(6), 425-448. http:// dx.doi.org/10.1002/per.416

Petrides, K. V., Sangareau, Y., Furnham, A., \& Frederickson, N. (2006). Trait emotional intelligence and children's peer relations at school. Social Development, 15, 537-547. http://dx.doi.org/10.1111/ j.1467-9507.2006.00355.x

Petrides, K. V., Vernon, P. A., Schermer, J. A., Lightart, L., Boomsma, D. I., \& Veselka, L. (2010). Relationships between trait emotional intelligence and the Big Five in the Netherlands. Personality and Individual Differences, 48(8), 906-910. http://dx.doi.org/10.1016/ j.paid.2010.02.019

Qualter, P., Whiteley, H., Hutchinson, J., \& Pope, D. (2007). Supporting the development of emotional intelligence competencies to ease the transition from primary to high school. Educational Psychology in Practice, 23(1), 79-95. http:// dx.doi.org/10.1080/02667360601154584

Richards, A., Ospina-Duque, J., BarreraValencia, M., Escobar-Rincón, J., ArdilaGutiérrez, M., Metzler, T., \& Marmar, C. (2011). Posttraumatic stress disorder, anxiety and depression symptoms, and psychosocial treatment needs in Colombians internally displaced by armed conflict: A mixed-method evaluation. Psychological Trauma: Theory, Research, Practice, and Policy, 3(4), 384-393. http:// dx.doi.org/10.1037/a0022257
Rimisp - Centro Latinoamericano para el Desarrollo Rural. (2012). Poverty and inequality (Latin American Report 2011. Summary). Santiago, Chile: Author.

Saadi, Z. E., Honarmand, M. M., Najarian, B., Ahadi, H., \& Askari, P. (2012). Evaluation of the effect of emotional intelligence training on reducing aggression in second year high school female students. Journal of American Science, 8(5), 209-212.

Saklofske, D. H., Austin, E. J., Mastoras, S. M., Beaton, L., \& Osborne, S. E. (2012). Relationships of personality, affect, emotional intelligence and coping with student stress and academic success: Different patterns of association for stress and success. Learning and Individual Differences, 22(2), 251-257. http:// dx.doi.org/10.1016/j.lindif.2011.02.010

Salovey, P., \& Mayer, J. D. (1990). Emotional intelligence. Imagination, Cognition, and Personality, 9, 185-211. http://dx.doi.org/10.2190/ DUGG-P24E-52WK-6CDG

Santesso, D. L., Reker, D. L., Schmidt, L. A., \& Segalowitz, S. J. (2006). Frontal electroencephalogram activation asymmetry, emotional intelligence, and externalizing behaviors in 10-year-old children. Child Psychiatry and Human Development, 36(3), 311- 328. http:// dx.doi.org/10.1007/s10578-005-0005-2

Seligman, M. E. P., Ernst, R. M., Guillham, J., Reivich, K., \& Linkins, M. (2009). Positive education: Positive psychology and classroom interventions. Oxford Review of Education, 35(3), 293-311. http:// dx.doi.org/10.1080/03054980902934563

Stelmach, B. L. (2011). A synthesis of international rural education issues and responses. The Rural Educator, 32(2), $32-42$.

Stough, C., Saklofske, D. H., \& Parker, J. (2009). Assessing emotional intelligence: Theory, research, and applications. New York, USA: Springer.

Torche, F. (2010). Economic crisis and inequality of educational opportunity 
in Latin America. Sociology of Education, 83(2), 85-110. http:// dx.doi.org/10.1177/0038040710367935

United Nations Educational, Scientific and Cultural Organization. (2005). Education for All. The Quality Imperative. Paris: Author.

United Nations Educational, Scientific and Cultural Organization. (2011). The hidden crisis: Armed conflict and education. Paris: Author.

Valsiner, J. (2012). The Oxford handbook of culture and psychology. New York: Oxford University Press.

Whitfield, L. (2012). How countries become rich and reduce poverty: A review of heterodox explanations of economic development. Development Policy Review, 30(3), 239-260. http://dx.doi.org/10.1111/ j.1467-7679.2012.00575.x

Zeidner, M., Matthews, G., \& Roberts, R. D. (2012). The emotional intelligence, health, and well-being nexus: What have we learned and what have we missed? Applied Psychology: Health and Well-Being, 4(1), 1-30. http://dx.doi.org/10.1111/ j.1758-0854.2011.01062.x

\section{Notes}

* Research article. 